\title{
Impact of Temperature and Material Variation on Mechanical Properties of Parts Fabricated with Fused Deposition Modelling (FDM) Additive Manufacturing
}

\author{
M. Hossein Sehhat ( $\nabla$ hsehhat@mst.edu ) \\ University of Missouri Rolla: Missouri University of Science and Technology https://orcid.org/0000- \\ 0002-7013-1642
}

Ali Mahdianikhotbesara

Farzad Yadegari

\section{Research Article}

Keywords: Fused Deposition Modeling, Design of Experiments (DOE), JMP, Mechanical Properties, PLA, PETG, ABS, Additive Manufacturing

Posted Date: February 9th, 2022

DOI: https://doi.org/10.21203/rs.3.rs-1079840/v2

License: (c) (i) This work is licensed under a Creative Commons Attribution 4.0 International License. Read Full License 


\section{Abstract}

Additive Manufacturing (AM) can be deployed for space exploration purposes, such as fabricating different components of robots' bodies. The produced AM parts should have desirable thermal and mechanical properties to withstand the extreme environmental conditions, including the severe temperature variations on moon or other planets which cause changes in parts' strengths and may fail their operation. Therefore, the correlation between operational temperature and mechanical properties of AM fabricated parts should be evaluated. In this study, three different types of polymers, including polylactic acid (PLA), polyethylene terephthalate glycol (PETG), and acrylonitrile butadiene styrene (ABS), were used in Fused Deposition Modeling (FDM) process to fabricate several parts. The mechanical properties of produced parts were then investigated at various temperatures to generate knowledge on the correlation between temperature and type of material. When varying the operational temperature during tensile tests, the material's glass transition temperature was found influential in determining the type of material failure. Among the materials used, ABS showed the best mechanical properties at all temperatures due to its highest glass transition temperatures. The results of statistical analysis indicated the temperature as the significant factor on tensile strength while the type of material was not a significant factor.

\section{Introduction}

The advent of Additive Manufacturing (AM) has revolutionized the part production methods [1][2]. While in conventional manufacturing methods the raw material should undergo several different manufacturing steps, such as forming, machining, welding, etc. [3][4], AM can produce the components in a layer-based single step fabrication process [5] with desirable mechanical properties [6][7][8]. Depending on the format of material feedstock, which can be powder, foil, paste, etc., the material feeding method to the AM process can be different [9][10]. In powder-based AM methods, powder spreadability dominates the material feeding process to the AM system [11], while in the Fused Deposition Modeling (FDM) process the ability to extrude polymer material to the AM system is a role-player [12].

The AM and its related developments, defects, and downsides have been studied in the literature in the recent past years. A novel technique for analyzing the in-situ 3D transient thermal variations in powderbed AM processes was developed by Lazoglu et al. [13][14]. This advanced model could track the material phases, porosity, and thermal properties, especially instantaneous transient temperature fields following the variations in time and laser path. This model can be very useful in fabrication of conductive tracks, resistors, electrodes, and heating elements using AM methods; such parts were produced by printing selectively distributed conductive and insulating locations per layer [15]; using the direct ink writing AM process, complex-geometry parts were printed with a feedstock mixture of carboxymethyl cellulose and graphite particles. Some solutions to avoid the defect of staircase effects on shell and solid components were proposed in [16]; they printed the material in a varied intra-layer thicknesses by utilizing an advanced multi-axis path planning model; the implemented efficient toolpaths aided in adjusting the form of top surface and keeping a high-quality part. In another work by the same group [17], a nonplanar 
helical slicing method was developed to create a single continuous 3D tool path (compared with 2.5D planar methods) with the goal of eliminating seam defects. The developed system benefited from a simplified extruder control without extra movements. In addition, a novel slicing method of the CAD model was used to fabricate spherical parts [18]; while conventionally the CAD model is sliced into planes, the proposed method innovatively sliced the CAD model into spherical shells, where the tool paths are guided to deposit the spherical layers. In addition to these defects, a disadvantage of AM is the high waste of material for production of complex-geometry parts composed of large overhangs, where filling the space between the overhang and the build plate is required. While conventional in-situ printing of support structures was useful in fabricating the parts with desirable dimensional accuracy, their removal post-processing was a waste of time and material. A solution to this downside was proposed in [19][20] [21], where an already produced reusable modular support considerably decreased the need for printing the in-situ support structures, reduced the material usage, and shortened the fabrication time. The modular support itself can be fabricated using the AM methods to meet the required complexity in their geometries [22].

In FDM process, following the part geometry data, the nozzle extrudes the polymer filament onto the build plate for the first part's layer [23]. Then, either the extruder or build plate moves to create the gap for the next layer. After that, the extruder prints the next layer on the previous layer. By repetition of this process, the final part is fabricated [24]. The FDM process parameters are build orientation, layer thickness, raster angle, extrusion temperature, and infill density [25]. These process parameters should be adjusted in a way that each printed track could be properly bounded to the side tracks and previous printed layer [26] [27].

One of the important applications of AM is in space exploration since it provides the benefit of part fabrication in just a single step [28]. Also, the rapid production of spare parts for exploration robots on the moon or other planets is another advantage of AM deployment in space exploration purposes [29]. Several components of robot's bodies should be fabricated in light weight but high strength to both use low amount of energy and properly perform the tasks. Polymers can be used to fabricate parts with light weights although the environmental conditions can considerably influence their mechanical properties [30]. The tensile properties, for instance, can be significantly affected by the variation in temperature [31]. At high temperatures the material may behave like a ductile material while at low temperatures the same material may show brittle performance [32]. Thus, for designing the components that operate in extreme thermal conditions, the relation between type of material, environmental conditions, and mechanical properties should be evaluated. Even the surface coating can have significant effects, as found in a work by Lazoglu et al. [33], where the impact of spray coating on the PLA parts fabricated by FDM was studied; although the coating didn't improve the tensile strengths, it considerably increased the samples' elongation.

In this study, the relation between thermal operational conditions and mechanical properties have been investigated. The parts were fabricated with three types of polymer, including polyethylene terephthalate glycol (PETG), polylactic acid (PLA), and acrylonitrile butadiene styrene (ABS). The parts were produced 
using FDM method. The statistical analysis was conducted on the results to determine the significant factors and their influence on mechanical properties.

\section{Materials And Methods}

Filaments of three thermoplastic materials, PETG, PLA, and ABS with filament diameter $1.75 \mathrm{~mm}$ were provided and their properties are shown in Table 1. The tensile coupons were loaded into the tensile testing machine, where they were pulled to breaking. Upon completion of these tests, the results were analyzed and material properties such as ultimate tensile strength (UTS) and modulus of elasticity (E) were determined. Tests were conducted according to ASTM D638 [34][35], except when modified in a few key areas. The tensile coupons were modified to promote consistent fracturing in the neck of the sample. Coupon neck widths were decreased from the ASTM standard, and the fillet from the grip to the neck was increased in both length and diameter. The modification stemmed from other research, showing this type of modification to improve the behavior of 3D printed tensile coupons under test [36]. The tensile testing machine used was an Instron 5969 outfitted with a $10 \mathrm{kN}$ load cell [37]. The strain rate used was 51/min, which is the minimum speed recommended in ASTM D638. The jaws utilized for this experiment were flat jaws with a maximum capacity of $50 \mathrm{kN}$. The jaws were tightened until snug then an additional $1 / 4$ turn was added to make sure the samples did not slip during the test. The machine set-up can be seen in Figure 1.

Table 1

The properties of polymers used in this study

\begin{tabular}{|lll|}
\hline Material & Glass transition temperature $\left({ }^{\circ} \mathrm{F}\right)$ & Ultimate tensile strength $(\mathrm{psi})$ \\
\hline PETG & 176 & 7079 \\
\hline PLA & 140 & 7964 \\
\hline ABS & 221 & 5872 \\
\hline
\end{tabular}

The tensile test samples were fabricated using a Prusa i3 printer. The used process parameters were $100 \%$ infill density (to eliminate interactions with infill patterns), $0.2 \mathrm{~mm}$ layer thickness, $30 \mathrm{~mm} / \mathrm{s}$ printing speed, and $0.5 \mathrm{~mm}$ nozzle diameter. The samples were printed at a $45^{\circ}$ angle on the print bed to ensure a majority of the layers were printed along the length of the part instead of at $45^{\circ}$. Finally, to prevent the crack propagation from the start or stop of the printer at the layer transition, it was made sure that the start and stop of each layer did not lie within the neck of the coupon. All of these specifications were kept constant for all of the samples. Figure 2 shows an instance of a printed tensile coupon of PLA.

The temperature was varied at three different levels of 40,65 , and $170^{\circ} \mathrm{F}$ to assess its impact on mechanical properties. For providing the $170^{\circ} \mathrm{F}$ (hot) operational temperature, the samples were immersed in hot water at $170^{\circ} \mathrm{F}$ until they reached a steady state temperature of $170^{\circ} \mathrm{F}$. These samples were then rapidly removed out of hot water with warm pliers and inserted into the tensile testing machine. A heat gun was used to create a warm environment around the sample and keep it at steady state 
temperature to limit heat transfer. For providing the $40^{\circ} \mathrm{F}$ (cold) operational temperature, the cold samples were brought down to $40^{\circ} \mathrm{F}$ while soaking in an ice-bath. To prevent moisture absorption into the material, samples were placed into a plastic bag before being soaked in the ice-bath. These samples were then removed from the cooler with cold pliers and inserted into the tensile testing machine. The temperature was verified with a FLIR thermal imaging camera during each test, an instance of which is shown in Figure 3. For the room temperature samples the room temperature was gathered before and during the testing to verify that it was kept constant; the lab's temperature was constant at $65^{\circ} \mathrm{F}$ throughout the test.

\section{Results And Discussion}

\subsection{PETG}

In order to determine the stress and strain of the various samples, the width, thickness, and gauge length of the tensile coupons were recorded. The gauge length of the tensile testing machine was set to 3.9 inches to keep it consistent among all materials and temperatures tested. The thickness, width, and the obtained UTS of the hot PETG samples are shown in Table 2.

Table 2

Dimensions and tensile strengths of hot PETG test coupons

\begin{tabular}{|llll|}
\hline Sample \# & Width (in) & Thickness (in) & UTS (psi) \\
\hline 1 & 0.245 & 0.195 & 2619 \\
\hline 2 & 0.247 & 0.199 & 2373 \\
\hline 4 & 0.246 & 0.199 & 1776 \\
\hline 5 & 0.245 & 0.194 & 2175 \\
\hline
\end{tabular}

The hot PETG samples after the tensile testing are shown in Figure 4. The hot PETG samples were tested until the UTS was reached, except sample \# 5 that went out of control and was fully separated. The PETG material behaved as a ductile material at the raised temperature $\left(170^{\circ} \mathrm{F}\right)$. The samples show the necking phenomenon same as ductile materials. Since $170^{\circ} \mathrm{F}$ is roughly $5 \%$ less than the glass transition temperature of $\mathrm{PETG}$, which is $176^{\circ} \mathrm{F}$, the inaccuracies of heating the samples with the heat gun could have led to the material passing the glass transition temperature. This resulted in the samples elongating more than the rest of the samples tested in this experiment. This finding suggests that the material behavior is in the glass transition state as it is neither brittle nor rubbery.

The thickness, width, and the obtained UTS of the cold PETG samples are shown in Table 3. The cold PETG samples as seen in Figure 5, were tested until fracture. The samples acted as a brittle material because the samples' temperature $\left(40^{\circ} \mathrm{F}\right)$ was $88 \%$ less than the glass transition temperature $\left(176^{\circ} \mathrm{F}\right)$. This indicated that the material behaved in the glassy state. 
Table 3

Dimensions and tensile strengths of cold PETG test coupons

\begin{tabular}{|llll|}
\hline Sample \# & Width (in) & Thickness (in) & UTS (psi) \\
\hline 1 & 0.250 & 0.190 & 6408 \\
\hline 2 & 0.249 & 0.195 & 6222 \\
\hline 4 & 0.249 & 0.197 & 6628 \\
\hline 5 & 0.250 & 0.197 & 6486 \\
\hline
\end{tabular}

The thickness, width, and the obtained UTS of the room temperature PETG samples are shown in Table 4. The room temperature PETG samples, as shown in Figure 6, resulted in a brittle fracture. This is because the material was still below the glass transition temperature in the glassy state.

Table 4

Dimensions and tensile strengths of room temperature PETG test coupons

\begin{tabular}{|llll|}
\hline Sample \# & Width (in) & Thickness (in) & UTS (psi) \\
\hline 1 & 0.251 & 0.200 & 6741 \\
\hline 2 & 0.251 & 0.200 & 6567 \\
3 & 0.249 & 0.198 & 6066 \\
\hline 4 & 0.251 & 0.198 & 6363 \\
\hline 5 & 0.251 & 0.200 & 6626 \\
\hline
\end{tabular}

The stress-strain graphs were developed with the results obtained from the tensile testing machine. The 5 samples of each temperature were averaged and plotted on the graph seen in Figure 7. The stiffness can also be qualitatively observed, where a steeper stress-strain curve slope indicates a stiffer material. The summary of the mean UTS and E of PETG at different temperatures is shown in Table 5.

Table 5

Summary of mechanical properties for PETG samples

\begin{tabular}{|lll|}
\hline Test Temperature $\left({ }^{\circ} \mathrm{F}\right)$ & Average UTS (psi) & Average E (psi) \\
\hline 40 & 6429 & 270,225 \\
\hline 65 & 6140 & 292,027 \\
\hline 170 & 1998 & 169,894 \\
\hline
\end{tabular}


The hot PLA test did not conclude with any useful data within the scope of this experiment. The PLA's glass transition temperature is $140^{\circ} \mathrm{F}$, which is roughly $20 \%$ lower than the $170^{\circ} \mathrm{F}$ temperature used in this experiment. This made the PLA samples within the rubbery state of the material. The first test of hot PLA samples took less than the preload force to make it yield. The stress-strain curve of these samples would have been a graph with a constant zero result.

The thickness, width, and UTS of the cold PLA samples can be seen in Table 6. The cold PLA samples as shown in Figure 8, were tested until fracture. The samples acted as a brittle material since the samples' temperature was $72 \%$ less than the glass transition temperature, indicating that they perform in the glassy state.

Table 6

Dimensions and tensile strengths of cold PLA test coupons

\begin{tabular}{|llll|}
\hline Sample \# & Width (in) & Thickness (in) & UTS (psi) \\
\hline 1 & 0.243 & 0.207 & 7664 \\
\hline 2 & 0.242 & 0.206 & 7751 \\
\hline 4 & 0.249 & 0.210 & 7734 \\
\hline 5 & 0.243 & 0.207 & 7888 \\
\hline
\end{tabular}

The thickness, width, and UTS of the room temperature PLA samples can be seen in Table 7. The room temperature PLA samples as shown in Figure 9, resulted in brittle fracture, i.e., these samples were still in the glassy state at roughly $46 \%$ of the glass transition temperature.

Table 7

Dimensions and tensile strengths of room temperature PLA test coupons

\begin{tabular}{|llll|}
\hline Sample \# & Width (in) & Thickness (in) & UTS (psi) \\
\hline 1 & 0.242 & 0.207 & 7209 \\
\hline 2 & 0.243 & 0.207 & 7241 \\
\hline 3 & 0.243 & 0.207 & 7218 \\
\hline 5 & 0.242 & 0.207 & 7166 \\
\hline
\end{tabular}

The stress-strain graphs were developed with the results obtained from the tensile testing machine. The 5 samples of each temperature were averaged and plotted on the graph shown in Figure 7.

The summary of the mean UTS and E of PLA at different temperatures is shown in Table 5. 
Table 8

Summary of mechanical properties for PLA samples

\begin{tabular}{|lll|}
\hline Test Temperature $\left({ }^{\circ} \mathrm{F}\right)$ & Average UTS (psi) & Average E (psi) \\
\hline 40 & 7761 & 431,666 \\
\hline 65 & 7225 & 463,336 \\
\hline
\end{tabular}

\subsection{ABS}

All ABS samples were successfully tested until fracture. The ABS tensile coupons exhibited signs of brittle failure at all temperatures. Out of all the materials tested, the failure mode of ABS was the most consistent across the tested temperature range. Due to its high glass transition temperature $\left(221^{\circ} \mathrm{F}\right)$, the ABS samples remained closer to the glassy state while being tested at high temperatures. The thickness, width, and UTS of the hot ABS samples can be seen in Table 9. Hot temperature samples showed some signs of necking, shown in Figure 11, as lighter-colored regions of stretched material near the fracture, but mostly exhibited signs of brittle fracture.

Table 9

Dimensions and tensile strengths of hot ABS test coupons

\begin{tabular}{|llll|}
\hline Sample \# & Width (in) & Thickness (in) & UTS (psi) \\
\hline 1 & 0.236 & 0.202 & 2473 \\
\hline 2 & 0.234 & 0.202 & 2271 \\
\hline 3 & 0.235 & 0.202 & 2508 \\
\hline 5 & 0.236 & 0.203 & 2445 \\
\hline
\end{tabular}

The thickness, width, and UTS of the cold ABS samples can be seen in Table 10. The cold ABS samples as shown in Figure 12, were tested until fracture. The samples acted as a brittle material because the deployed temperature was $82 \%$ less than the glass transition temperature, indicating that the material was in the glassy state. 
Table 10

Dimensions and tensile strengths of cold ABS test coupons

\begin{tabular}{|llll|}
\hline Sample \# & Width (in) & Thickness (in) & UTS (psi) \\
\hline 1 & 0.246 & 0.201 & 5473 \\
\hline 3 & 0.248 & 0.203 & 5760 \\
\hline 4 & 0.245 & 0.199 & 5624 \\
\hline 5 & 0.238 & 0.199 & 5183 \\
\hline
\end{tabular}

The thickness, width, and UTS of the room temperature ABS samples can be seen in Table 11. The room temperature ABS samples as seen in Figure 13, resulted in brittle fractures as these samples were still in the glassy state at roughly $29 \%$ of the glass transition temperature.

Table 11

Dimensions and tensile strengths of room temperature ABS test coupons

\begin{tabular}{|llll|}
\hline Sample \# & Width (in) & Thickness (in) & UTS (psi) \\
\hline 1 & 0.242 & 0.203 & 4497 \\
\hline 2 & 0.244 & 0.202 & 5010 \\
\hline 3 & 0.236 & 0.202 & 4988 \\
\hline 4 & 0.243 & 0.202 & 5031 \\
\hline 5 & 0.245 & 0.200 & 5258 \\
\hline
\end{tabular}

The stress-strain graphs were developed with the results obtained from the tensile testing machine. The 5 samples of each temperature were averaged and plotted on the graph shown in Figure 14.

The summary of the mean UTS and E of ABS at different temperatures is shown in Table 12.

Table 12

Summary of mechanical properties for ABS samples

\begin{tabular}{|lll|}
\hline Test Temperature $\left({ }^{\circ} \mathrm{F}\right)$ & Average UTS (psi) & Average E (psi) \\
\hline 40 & 5473 & 357,714 \\
\hline 65 & 4902 & 369,968 \\
\hline 170 & 2415 & 261,100 \\
\hline
\end{tabular}

\subsection{Statistical Analysis}


The powerful statistical commercial software of JMP [38] was used to conduct statistical analysis to evaluate the results. The data collected was analyzed using factorial statistical design. The 2 variable factors are type of material and temperature. The type of material has 3 levels of PETG, PLA, and ABS, and the temperature has 3 levels of 170,65 , and $40^{\circ} \mathrm{F}$. The response variable was considered as UTS. The design of experiment can be denoted as a $3^{2}$ factorial, with 9 different test combinations. Each test condition was replicated 5 times, i.e., total of 45 tensile tests were performed. The data used for analysis is provided in Table 13, which shows the UTS for various materials and temperatures. By performing analysis of variance (ANOVA) on this data, the combination of best material and temperature will be statistically determined, by considering that the higher strength and modulus is desired. 
Table 13

Test combinations for statistical analysis

\begin{tabular}{|c|c|c|}
\hline Temperature $\left({ }^{\circ} \mathrm{F}\right)$ & Material & UTS (psi) \\
\hline 170 & PETG & 2619 \\
\hline 170 & PETG & 2373 \\
\hline 170 & PETG & 1776 \\
\hline 170 & PETG & 2175 \\
\hline 170 & PETG & 2127 \\
\hline 40 & PETG & 6408 \\
\hline 40 & PETG & 6222 \\
\hline 40 & PETG & 6628 \\
\hline 40 & PETG & 6486 \\
\hline 40 & PETG & 6706 \\
\hline 65 & PETG & 6741 \\
\hline 65 & PETG & 6567 \\
\hline 65 & PETG & 6066 \\
\hline 65 & PETG & 6363 \\
\hline 65 & PETG & 6626 \\
\hline 170 & PLA & 0 \\
\hline 170 & PLA & 0 \\
\hline 170 & PLA & 0 \\
\hline 170 & PLA & 0 \\
\hline 170 & PLA & 0 \\
\hline 40 & PLA & 7664 \\
\hline 40 & PLA & 7751 \\
\hline 40 & PLA & 7734 \\
\hline 40 & PLA & 7888 \\
\hline 40 & PLA & 7832 \\
\hline 65 & PLA & 7209 \\
\hline 65 & PLA & 7241 \\
\hline
\end{tabular}

Page $11 / 23$ 


\begin{tabular}{|lll|}
\hline Temperature $\left({ }^{\circ} \mathrm{F}\right)$ & Material & UTS (psi) \\
\hline 65 & PLA & 7218 \\
65 & PLA & 7166 \\
65 & PLA & 7335 \\
170 & ABS & 2473 \\
170 & ABS & 2271 \\
\hline 170 & ABS & 2508 \\
170 & ABS & 2445 \\
\hline 170 & ABS & 2508 \\
\hline 40 & ABS & 5473 \\
40 & ABS & 5760 \\
\hline 40 & ABS & 5624 \\
\hline 40 & ABS & 5183 \\
\hline 40 & ABS & 5422 \\
\hline 65 & ABS & 4497 \\
\hline 65 & ABS & 5010 \\
\hline 65 & ABS & 4988 \\
\hline 65 & ABS & 5031 \\
\hline & ABS & 5258 \\
\hline
\end{tabular}

The results of a two-way ANOVA with significance level $5 \%$ are shown in Table 14 . The P-value for this experiment was found 0.002 . Thus, it is concluded that the UTS results of combinations of material and temperature are statistically significant different.

Table 14. Results of ANOVA generated by JMP Software

\begin{tabular}{|lrrrr|}
\hline \multicolumn{5}{l}{ Analysis of Variance } \\
Source & DF & $\begin{array}{r}\text { Sum of } \\
\text { Squares }\end{array}$ & Mean Square & F Ratio \\
Model & 5 & 105616419 & 21123284 & 4.6579 \\
Error & 39 & 176862039 & 4534924.1 & Prob > F \\
C. Total & 44 & 282478458 & & $0.0020^{*}$
\end{tabular}


The results of main effect tests and their interaction are shown in Table 15. Considering the significance level of $5 \%$, the interaction term was not statistically significant (P-value 0.1903 ). Considering the main effects, the type of material was not a significant factor (P-value 0.5556$)$ while the temperature was a significant factor (P-value 0.0001). The temperature variable contributed significantly to the change in ultimate strength. The material of the sample had less effect on the change in strength, particularly at room temperature. This can also be noted by the behavior of the confidence curves; the confidence curve crosses the horizontal residual line in Figure 15, so the effect of temperature is significant. The confidence curves do not display this behavior in Figure 16 and Figure 17, so the effects of material and interaction term (temperature-material) are not significant.

Table 15. The results of main effect tests and their interaction

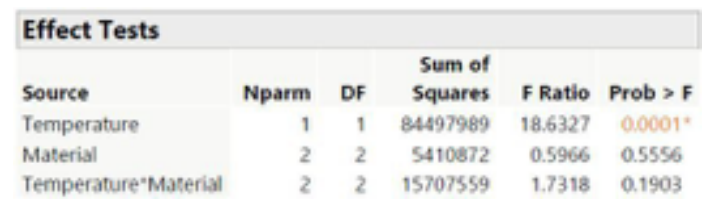

\section{Conclusion}

In this study, the impact of temperature on mechanical properties of polymers fabricated with Fused Deposition Modeling (FDM) was investigated. Three types of thermoplastic polymers, including polylactic acid (PLA), polyethylene terephthalate glycol (PETG), and acrylonitrile butadiene styrene (ABS) were used to fabricate tensile coupons. The tensile tests were performed at three temperatures of 40,65 , and $170^{\circ} \mathrm{F}$. The JMP program was used to statistically analyze the results. It was found that the temperature was the significant factor while neither the type of material nor the interaction term (temperature-material) had any significant effects on tensile strengths. At elevated temperatures, ABS maintained greater strength and stiffness than PLA and PETG. At lower temperatures, ABS is not as strong by either measure; however, parts can be designed to account for the lower yield strength and stiffness, while it is significantly more difficult to design a part to handle the effects of extreme temperature.

\section{Declarations}

\section{a. Funding}

No funds, grants, or other support was received.

b. Conflicts of interest/Competing interests

The authors declare that they have no conflict of interest.

c. Availability of data and material

The raw/processed data required to reproduce these findings will be made available on request.

d. Code availability 
Not applicable

\section{Compliance with ethical standards}

e. Ethics approval

The manuscript contains original ideas which have never been published before in other journals.

f. Consent to participate

This study is not a human transplantation study. No consent needed for this paper.

g. Consent for publication

The authors declare their consent for publication.

\section{References}

1. Committee F42 on Additive Manufacturing Technologies (2021) (n.d.). https://www.astm.org/COMMITTEE/F42.htm

2. Nezhadfar PD, Thompson S, Saharan A, Phan N, Shamsaei N (2021) Fatigue and Failure Analysis of an Additively Manufactured Contemporary Aluminum Alloy, in: Miner. Met. Mater. Ser. Springer Science and Business Media Deutschland GmbH 212-219. https://doi.org/10.1007/978-3-03065396-5_31

3. Formability Investigation for Perforated Steel Sheets (2021) (n.d.). https://mobilityrxiv.sae.org/preprint/formability-investigation-for-perforated-steel-sheets--sae-pp00182

4. Mahdianikhotbesara A, Sehhat MH, Hadad M (2021) Experimental Study on Micro-Friction Stir Welding of Dissimilar Butt Joints Between Al 1050 and Pure Copper, Metallogr. Microstruct. Anal. (2021) 1-16. https://doi.org/10.1007/S13632-021-00771-5

5. Sehhat MH, Behdani B, Hung C, Ali H (2021) Development of an Empirical Model on Melt Pool Variation in Laser Foil Printing Additive. Manufacturing Process Using Statistical Analysis

6. Ghadimi H, Jirandehi AP, Nemati S, Guo S (2021) Small-sized specimen design with the provision for high-frequency bending-fatigue testing, Fatigue Fract. Eng Mater Struct. https://doi.org/10.1111/FFE.13589

7. Muhammad M, Nezhadfar PD, Thompson S, Saharan A, Phan N, Shamsaei N (2021) A comparative investigation on the microstructure and mechanical properties of additively manufactured aluminum alloys. Int J Fatigue 146:106165. https://doi.org/10.1016/J.IJFATIGUE.2021.106165

8. Jirandehi AP, Khonsari MM (2021) On the determination of cyclic plastic strain energy with the provision for microplasticity. Int J Fatigue 142:105966. https://doi.org/10.1016/J.IJFATIGUE.2020.105966 
9. Moghadasi M, Du W, Li M, Pei Z, Ma C (2020) Ceramic binder jetting additive manufacturing: Effects of particle size on feedstock powder and final part properties. Ceram Int 46:16966-16972. https://doi.org/10.1016/j.ceramint.2020.03.280

10. Hung CH, Chen WT, Sehhat MH, Leu MC (2020) The effect of laser welding modes on mechanical properties and microstructure of $304 \mathrm{~L}$ stainless steel parts fabricated by laser-foil-printing additive manufacturing. Int J Adv Manuf Technol 1-11. https://doi.org/10.1007/s00170-020-06402-7

11. Sehhat MH, Mahdianikhotbesara A (2021) Powder spreading in laser-powder bed fusion process, 23 89. https://doi.org/10.1007/s10035-021-01162-x

12. Behdani B, Senter M, Mason L, Leu M, Park J (2020) Numerical Study on the Temperature-Dependent Viscosity Effect on the Strand Shape in Extrusion-Based Additive Manufacturing. J Manuf Mater Process 4:46. https://doi.org/10.3390/jmmp4020046

13. Kundakcioglu E, Lazoglu I, Rawal S (2015) 851 Transient thermal modeling of laser-based additive manufacturing for 3D freeform structures, Int. J. Adv. Manuf. Technol. 85 (2015) 493-501. https://doi.org/10.1007/S00170-015-7932-2

14. Kundakcıoğlu E, Lazoglu I, Poyraz Ö, Yasa E, Cizicioğlu N (2018) 959 Thermal and molten pool model in selective laser melting process of Inconel 625, Int. J. Adv. Manuf. Technol. 95 (2018) 3977-3984. https://doi.org/10.1007/S00170-017-1489-1

15. Khan SA, Lazoglu I (2019) Development of additively manufacturable and electrically conductive graphite-polymer composites. Prog Addit Manuf 2019 52:153-162. https://doi.org/10.1007/S40964-019-00102-9

16. Isa MA, Lazoglu I (2019) Five-axis additive manufacturing of freeform models through buildup of transition layers. https://doi.org/10.1016/j.jmsy.2018.12.002

17. Yigit IE, Lazoglu I, Lazoglu I (2019) Helical slicing method for material extrusion-based robotic additive manufacturing 5-axis Additive Manufacturing System View project Development of An Open-Architecture Rapid Prototyping System View project Helical slicing method for material extrusion-based robotic additive manufacturing, 4 225-232. https://doi.org/10.1007/s40964-01900090-w

18. Yigit IE, Lazoglu I (2020) Spherical slicing method and its application on robotic additive manufacturing. Prog Addit Manuf 2020 54:387-394. https://doi.org/10.1007/S40964-020-00135-5

19. Yigit IE, Isa M, Lazoglu I (2018) Additive Manufacturing with Modular Support Structures, https://doi.org/10.26153/TSW/17208

20. Isa MA, Yiğit IE, Lazoglu I (2018) Analysis of Build Direction in Deposition-Based Additive Manufacturing of Overhang Structures, https://doi.org/10.26153/TSW/17156

21. Yigit IE, Lazoglu I (2019) Dynamic Build Bed for Additive Manufacturing, https://doi.org/10.26153/TSW/17381

22. Yigit IE, Khan SA, Lazoglu I, Yigit IE, Khan SA Robotic Additive Manufacturing of Tooling for Composite Structures Development of An Open-Architecture Rapid Prototyping System View project 
Additive Manufacturing with Funtional Materials Viewproject ROBOTIC ADDITIVE MANUFACTURING OF TOOLING FOR COMPOSITE STRUCTURES, (n.d.).

23. Bellehumeur C, Li L, Sun Q, Gu P (2004) Modeling of Bond Formation Between Polymer Filaments in the Fused Deposition Modeling Process. J Manuf Process 6:170-178.

https://doi.org/10.1016/S1526-6125(04)70071-7

24. Carneiro OS, Silva AF, Gomes R (2015) Fused deposition modeling with polypropylene. Mater Des 83:768-776. https://doi.org/10.1016/J.MATDES.2015.06.053

25. Wang C, Xu Y, Xia J, - Z, Shen H, Hua S, Yang J, Zhang J-L, Kuo H, Liu G, Prayitno F, Imaduddin Z, Arifin You may also like Multi-scale hierarchical scaffolds with aligned micro-fibers for promoting cell alignment Effect of Fabrication Parameters and Material Features on Tensile Strength of FDM Built Parts The Importance of Quantum Pressure of Fuzzy Dark Matter on Ly Forest Recent Progress of Fused Deposition Modeling (FDM) 3D Printing: Constructions, Parameters and Processings, (n.d.). https://doi.org/10.1088/1757-899X/1096/1/012045

26. Schöppner V, Bagsik A, Paderborn K (2011) Mechanical properties of fused deposition modeling parts manufactured with ULTEM\&z.ast9085 Design and Optimization of Wave-Dispersion Screws View. project MECHANICAL PROPERTIES OF FUSED DEPOSITION MODELING PARTS MANUFACTURED WITH ULTEM*9085

27. Vicente CMS, Martins TS, Leite M, Ribeiro A, Reis L (2020) Influence of fused deposition modeling parameters on the mechanical properties of ABS parts, Polym. Adv Technol 31:501-507. https://doi.org/10.1002/PAT.4787

28. Studies into Additive Manufacturing for In-Space Manufacturing (2021) : Student Research Papers | SAE eBooks | IEEE Xplore, (n.d.). https://ieeexplore.ieee.org/book/8503552

29. Crockete R, Petersen D, Cooper KFUSED DEPOSITION MODELING IN MICROGRAVITY, (n.d.).

30. Shofner ML, Lozano K, Rodríguez-Macías FJ, Barrera EV (2003) Nanofiber-reinforced polymers prepared by fused deposition modeling. J Appl Polym Sci 89:3081-3090. https://doi.org/10.1002/APP.12496

31. Zhou Y, Nyberg T, Xiong G, Liu D (2016) Temperature Analysis in the Fused Deposition Modeling Process, Proc. - 3rd Int. Conf. Inf. Sci. Control Eng. ICISCE 2016. (2016) 678-682. https://doi.org/10.1109/ICISCE.2016.150

32. Şerban DA, Weber G, Marşavina L, Silberschmidt VV, Hufenbach W (2013) Tensile properties of semicrystalline thermoplastic polymers: Effects of temperature and strain rates. Polym Test 32:413-425. https://doi.org/10.1016/J.POLYMERTESTING.2012.12.002

33. Abdulwahab M, Bijanzad A, Khan SA, Lazoglu I (2021) Effects of polyurea coating on the elastoplastic behavior of additively manufactured PLA specimens, Prog. Addit. Manuf. (2022) 1-8. https://doi.org/10.1007/S40964-021-00242-X

34. ASTM D638 - 14 Standard Test Method for Tensile Properties of Plastics (2021) (n.d.). https://www.astm.org/Standards/D638 
35. Samykano M, Selvamani SK, Kadirgama K, Ngui WK, Kanagaraj G, Sudhakar K Mechanical property of FDM printed ABS: influence of printing parameters, (n.d.). https://doi.org/10.1007/s00170-01903313-0

36. Lanzotti A, Grasso M, Staiano G, Martorelli M (2015) The impact of process parameters on mechanical properties of parts fabricated in PLA with an open-source 3-D printer. Rapid Prototyp J 21:604-617. https://doi.org/10.1108/RPJ-09-2014-0135/FULL/XML

37. Soltaninejad M, Soltaninejad M, K FS, Moshizi MK, Sadeghi V, Jahanbakhsh P (2021) Environmentalfriendly mortar produced with treated and untreated coal wastes as cement replacement materials, Clean Technol. Environ. Policy 1 (2021) 1-18. https://doi.org/10.1007/S10098-021-02204-X

38. Statistical Software | JMP Software from SAS (2021) (n.d.). https://www.jmp.com/en_us/home.html

\section{Figures}




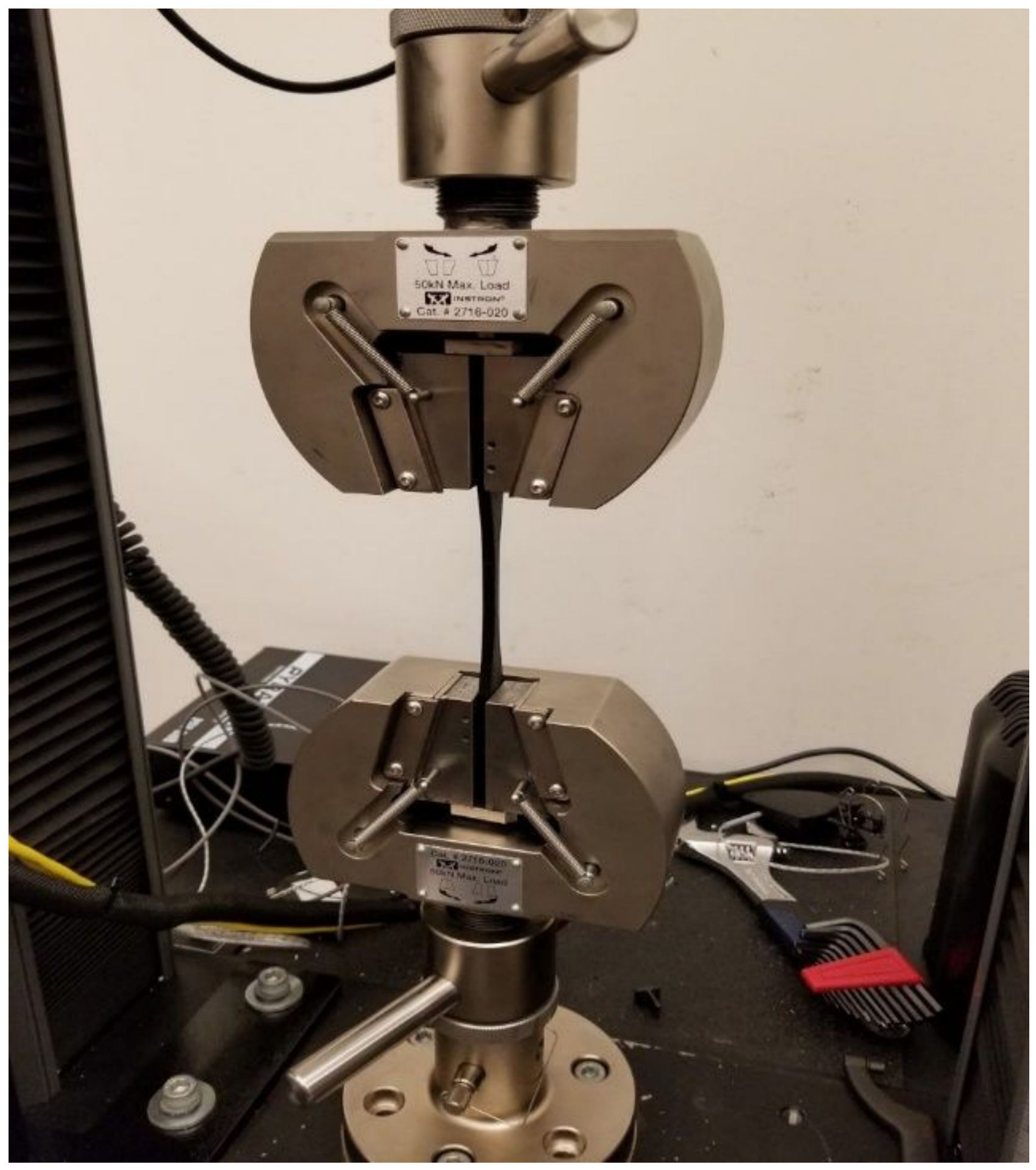

\section{Figure 1}

An instance of tensile testing setup used for characterization of mechanical properties. 

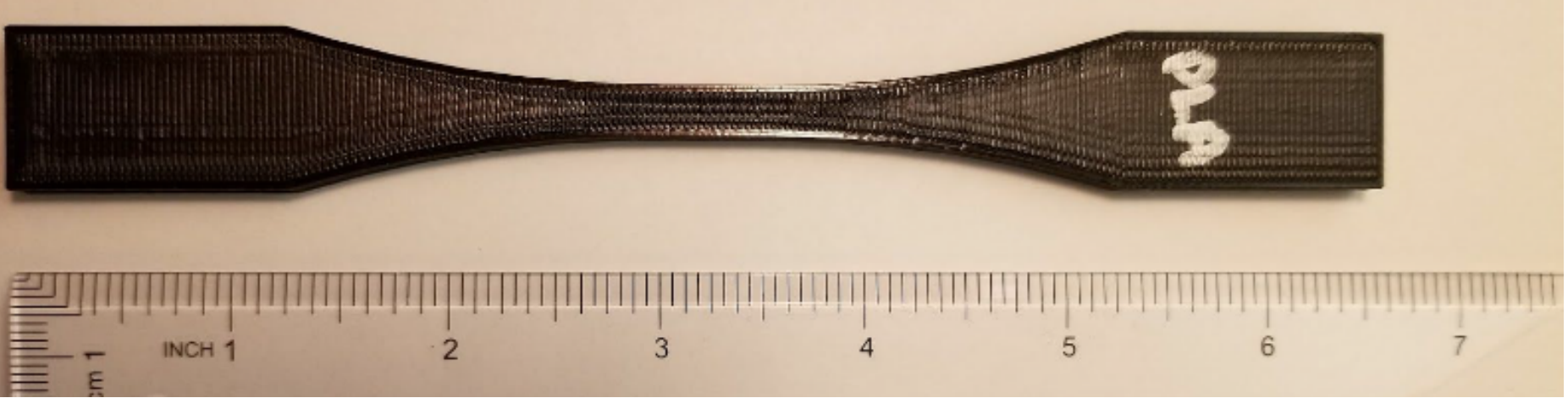

Figure 2

An instance of a printed tensile coupon of PLA.

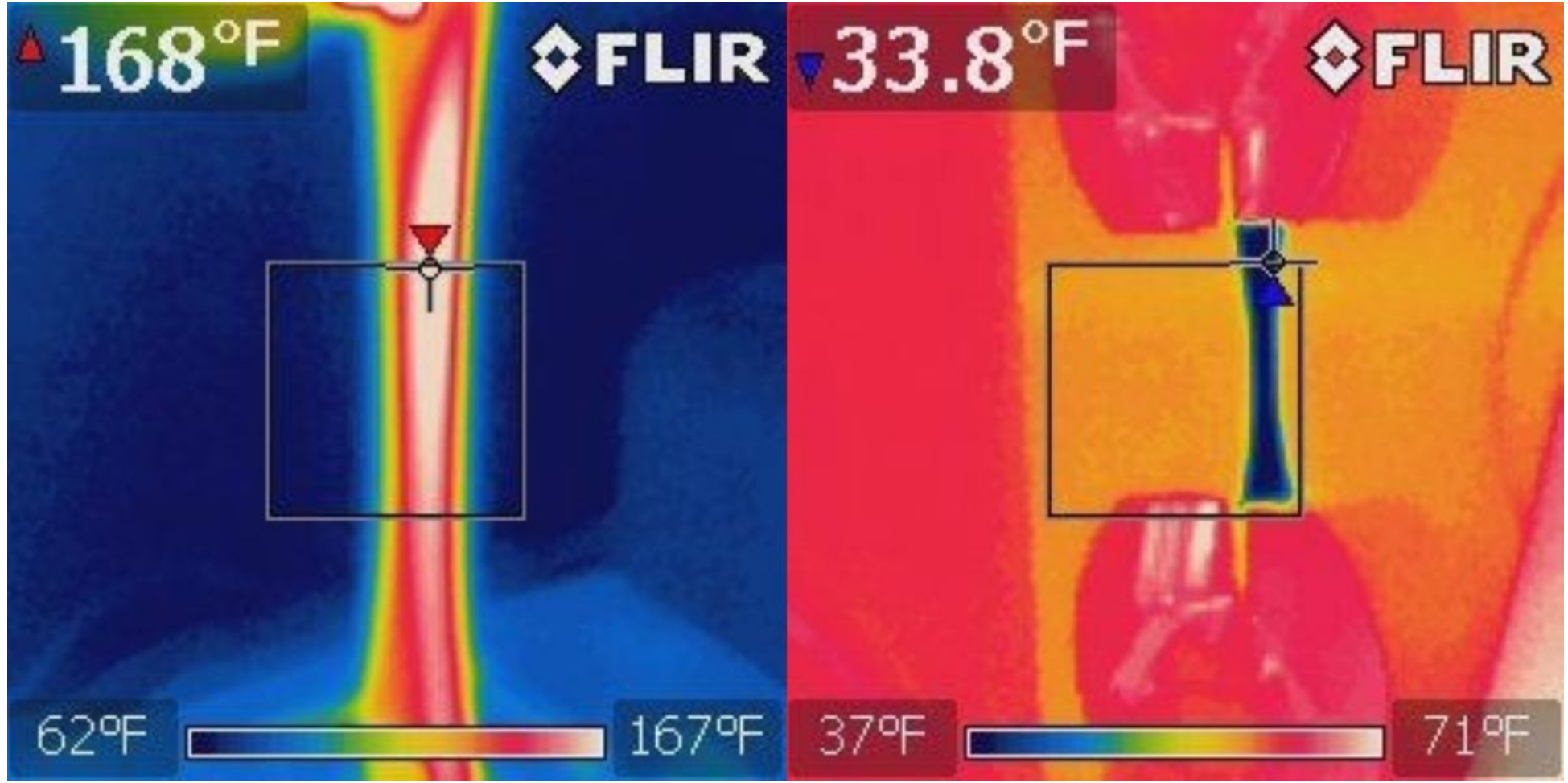

Figure 3

FLIR images of (a) hot $\left(170^{\circ} \mathrm{F}\right)$, and $(\mathrm{b})$ cold $\left(40^{\circ} \mathrm{F}\right)$ tensile samples. 


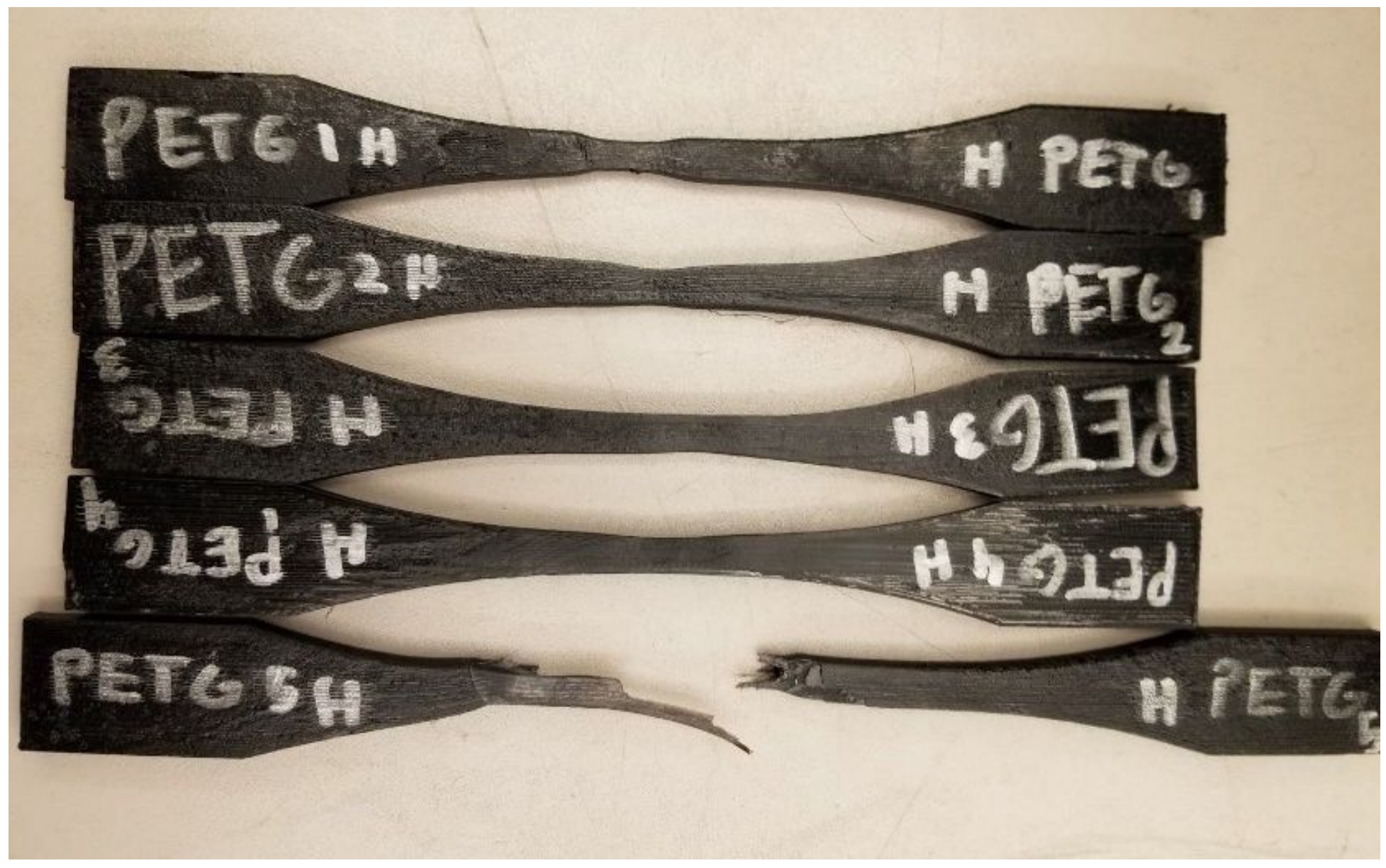

Figure 4

Hot temperature $\left(170^{\circ} \mathrm{F}\right)$ PETG samples after tensile testing. 


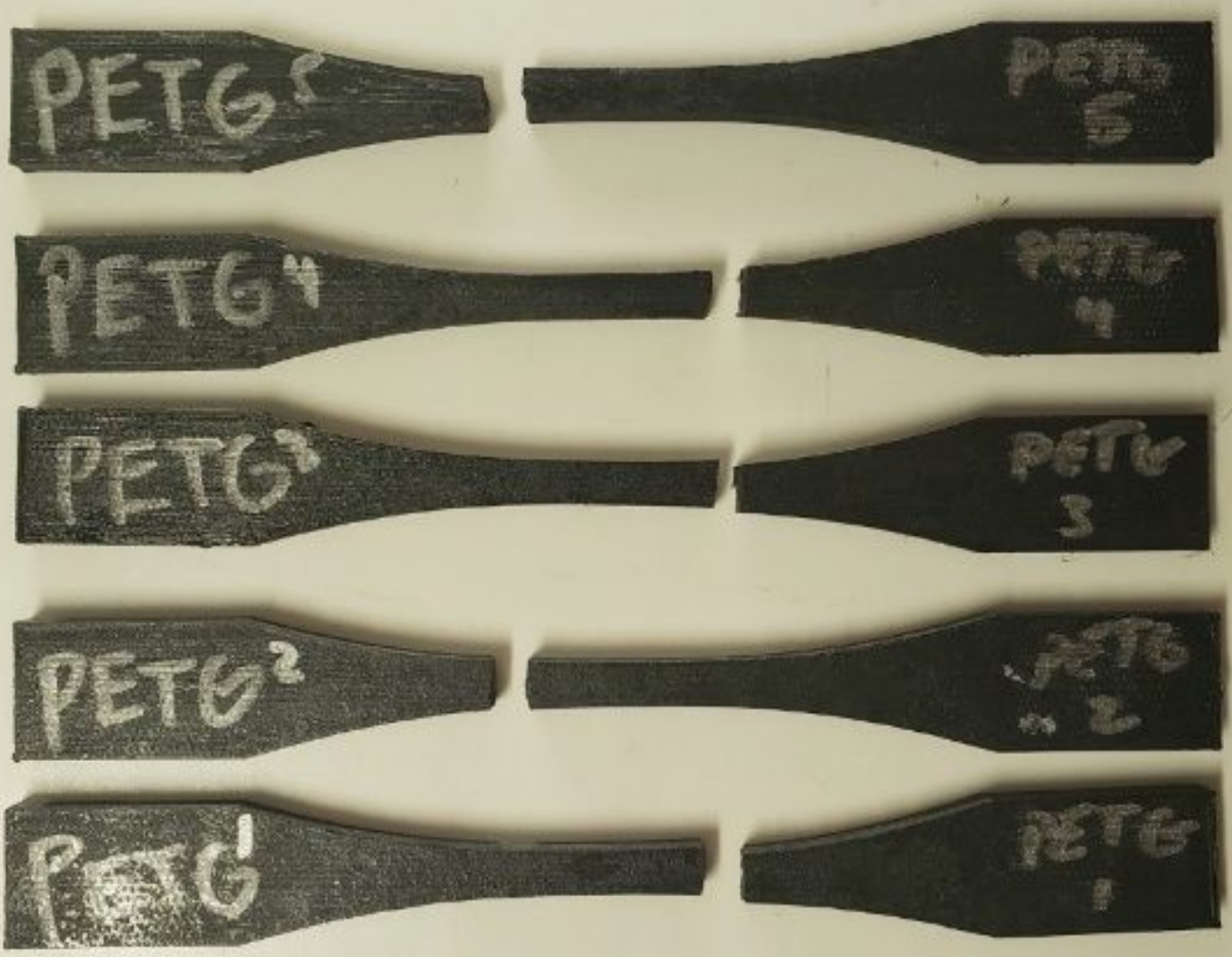

\section{Figure 5}

Cold temperature $\left(40^{\circ} \mathrm{F}\right)$ PETG samples after tensile testing.

\section{Figure 6}

Room temperature $\left(65^{\circ} \mathrm{F}\right)$ PETG samples after tensile testing.

\section{Figure 7}

The stress-strain curve for PETG samples at different temperatures.

Figure 8 
Cold $\left(40^{\circ} \mathrm{F}\right)$ PLA samples after tensile testing.

Figure 9

Room temperature $\left(65^{\circ} \mathrm{F}\right)$ PLA samples after tensile testing.

Figure 10

The stress-strain curve for PLA samples at different temperatures.

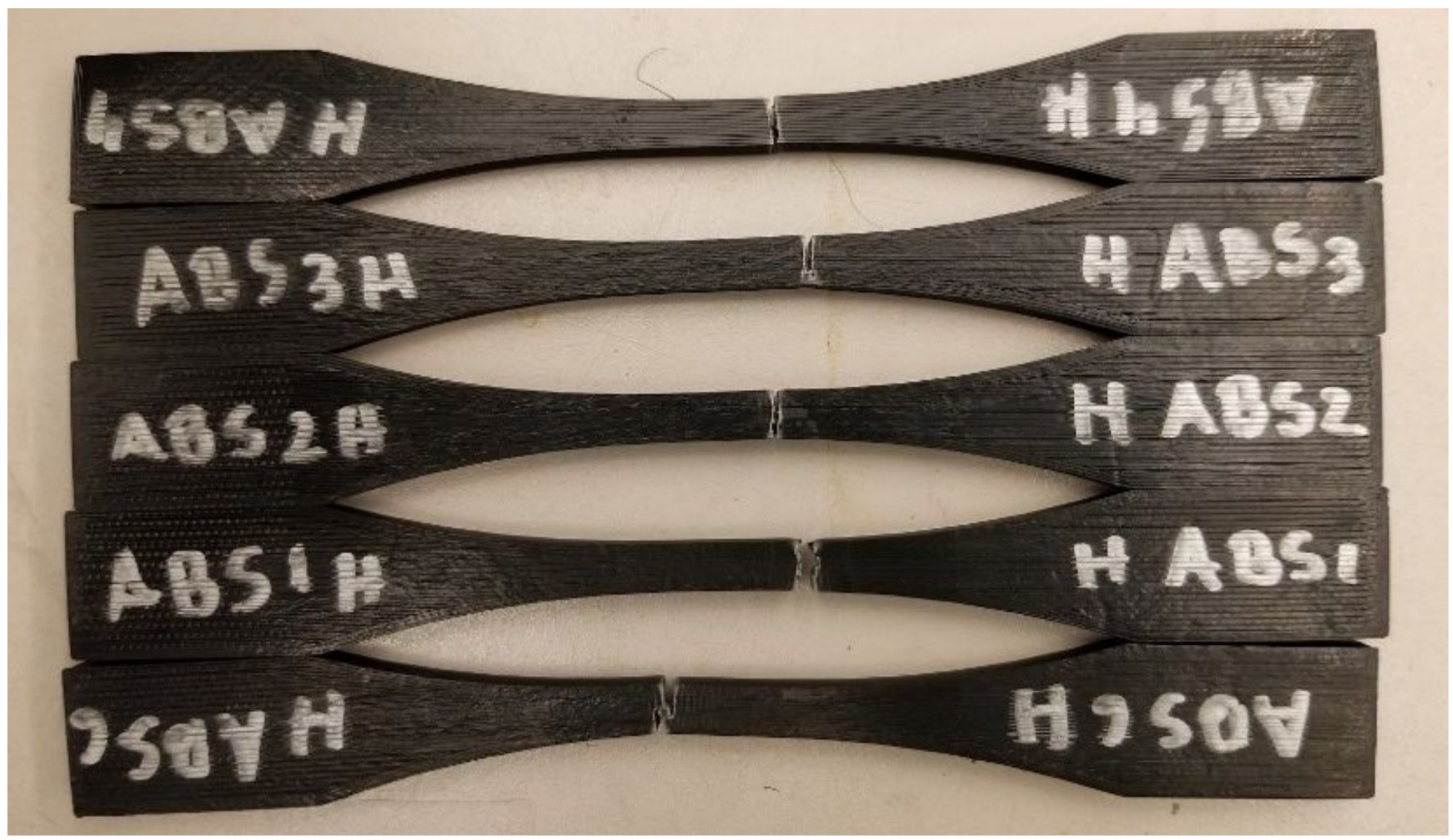

Figure 11

Hot $\left(170^{\circ} \mathrm{F}\right) \mathrm{ABS}$ samples after tensile testing.

Figure 12

Cold $\left(40^{\circ} \mathrm{F}\right) \mathrm{ABS}$ samples after tensile testing. 


\section{Figure 13}

Room temperature $\left(65^{\circ} \mathrm{F}\right) \mathrm{ABS}$ samples after tensile testing.

\section{Figure 14}

The stress-strain curve for ABS samples at different temperatures.

\section{Figure 15}

The confidence curve for effect of temperature on UTS.

\section{Figure 16}

The confidence curve for effect of material on UTS.

\section{Figure 17}

The confidence curve for effect of interaction term (temperature-material) on UTS. 